\title{
Women's Experience with Socio-Economic Factors Associated with Perinatal Morbidity and Mortality in Lusaka and Mumbwa Districts of Zambia
}

\author{
Maimbolwa Connie Margaret ${ }^{1}{ }^{*}$, Mukwato Katowa Patricia ${ }^{1}$, Muleya Mutinta ${ }^{1}$, \\ Kwaleyela Concepta1, Kalusopa Mwiinga Victoria', Emmanuel Musenge1, \\ Jon Oyvind Odland2,3, Babil Stray-Pedersen2,3 \\ ${ }^{1}$ School of Nursing Sciences, University of Zambia, Lusaka, Zambia \\ ${ }^{2}$ Faculty of Health Sciences, University of Tromsø, Tromsø, Norway \\ ${ }^{3}$ Faculty of Health Sciences, University of Oslo, Oslo, Norway \\ Email: *mmaimbolwa@yahoo.com, patriciakatowamukwato@gmail.com,cmmuleya@gmail.com,ckwaleyela@gmail.com, \\ victoriakalusopa@gmil.com, emmanuel.musenge@unza.zm, jon.oyvind.odland@uit.no, babil.stray-pedersen@medisin.uio.no
}

How to cite this paper: Margaret, M.C. Patricia, M.K., Mutinta, M., Concepta, K., Victoria, K.M., Musenge, E., Odland, J.O. and Stray-Pedersen, B. (2019) Women's Experience with Socio-Economic Factors Associated with Perinatal Morbidity and Mortality in Lusaka and Mumbwa Districts of Zambia. Health, 11, 733-754. https://doi.org/10.4236/health.2019.116061

Received: April 3, 2019

Accepted: June 15, 2019

Published: June 18, 2019

Copyright $\odot 2019$ by author(s) and Scientific Research Publishing Inc. This work is licensed under the Creative Commons Attribution International License (CC BY 4.0).

http://creativecommons.org/licenses/by/4.0/ c) (i) Open Access

\begin{abstract}
Background: More than half a million women and four million infants are reported to die every year due to complications related to pregnancy and child bearing. The efforts to improve quality maternity care have been on the World Health Organization member countries' agenda. Zambia has been striving to reduce maternal mortality by ensuring universal access to maternal and child health care services. Our study aimed to explore women's experience with socio-economic factors associated with perinatal morbidity and mortality in Lusaka and Mumbwa districts, Zambia. Methodology: This hermeneutic phenomenological study was conducted at four health facilities in Mumbwa and Lusaka Districts of Zambia. A purposeful sample of 45 consenting women organized in four groups was selected. Each group comprised of 11 to 12 women. The focus group discussion guide was used to direct the discussion and the Olympus Digital Voice Recorder WS-852 (Olympus Corporation, Shinjuku, Tokyo, Japan) was used to record the discussions. The audio data was manually transcribed and verbatim transcript analyzed using ATLAS.ti 8.0 qualitative data software (ATLAS.ti Scientific Software Development $\mathrm{GmbH}$, Berlin, Germany) to ascertain patterns of relationships between themes and quotations. Results: Money, husbands and family support, adequate health care resources, and good nurses attitude simplify the burden of pregnancy, delivery and child rearing for the health care providers, mothers and society. Conclusion: Having money and all the necessary resources
\end{abstract}


during pregnancy simplifies the burden of pregnancy, delivery and child rearing for the health care providers, mothers and society. Women are still ignorant and believe in myths and need information on the dangers of depending on herbs and God in preparation for labor and care of the new born, but also seek help from qualified medical personnel when labor starts. Nurse's attitude needs to change to ensure a reduction in women and newborn mortalities. Nurses were mentioned as the cause of mortality among women and newborn. Recommendations: There's a need for training of nurses and other health care workers on self-awareness of attitudes. Women should be empowered with resources that facilitate labor and delivery. Midwives and health care providers should take responsibility for evaluating and correcting the beliefs and traditional practices of the community. Training should be planned for raising awareness in order to support beneficial practices and prevent harmful ones.

\section{Keywords}

Maternity Care, Antenatal Care, Postnatal Care, Women's Health, Quality of Care, Midwifery

\section{Introduction}

Globally, pregnancy and childbirth are the leading causes of death among women in the reproductive age. More than half a million women and four million infants are reported to die every year due to complications related to pregnancy and childbearing. Approximately 830 women die from pregnancy- or childbirth-related complications around the world every day. In 2015, nearly 303,000 women died during and following pregnancy and childbirth [1] [2]. The ratios could be higher in developing countries where over $99 \%$ of maternal deaths occur [3] [4]. There are several socioeconomic factors that influence women's experience of the quality maternity care services they receive. Among them include economic stability, support from spouses, extended family and the community, attitude of health personnel and traditional practice [5]. The efforts to improve maternity care have been on the WHO member countries' agenda. There have been collective efforts to improve access and use of maternal health care services. However, the reduction of maternal and neonatal mortality has remained a public health challenge in developing countries, mostly in sub-Saharan Africa [6] [7].

In 2015, the maternal mortality ratio in developing countries was 239 per 100,000 live births contrasted with 12 per 100,000 live births in developed countries [3] [4]. In addition, the risk of maternal mortality is highest for adolescent girls under 15 years old and complications in pregnancy and childbirth is a leading cause of death among adolescent girls in developing countries. The major complications that account for nearly $75 \%$ of all maternal deaths include severe bleeding and infection after childbirth, pre-eclampsia and eclampsia, com- 
plications from delivery and unsafe abortion [6]. Most maternal deaths are preventable, as the health-care solutions to prevent or manage complications are well known. There is a need for all women to access antenatal care in pregnancy, skilled care during childbirth, and care and support in the weeks after childbirth [7]. According to [7], an estimated 2.7 million newborn babies died and an additional 2.6 million were stillborn in 2015. It is particularly important that all births are attended by skilled health professionals, as timely management and treatment can make the difference between life and death for both the mother and the stillborn baby [7].

In 2015, only $40 \%$ of all pregnant women in low-income countries had the recommended antenatal care visits. To improve maternal health, barriers that limit access to quality maternal health services must be identified and addressed at all levels of the health care delivery system. However, underlying the estimates of effectiveness is the assumption that interventions delivered must be of good quality. While many countries have been successful in increasing utilization of services through demand promotion programmes, these efforts are often accompanied by poor or declining quality of services. WHO advocates for more affordable and effective treatments, design training materials and guidelines for health workers, and supports countries to implement policies and programmes and monitor progress [8] [9]. Therefore, during the United Nations (UN) General Assembly of 2015, UN Secretary-General Ban Ki-moon launched the Global Strategy for Women's, Children's and Adolescents' Health, 2016-2030 [7] [10]. This Strategy is a road map for the post-2015 Millennium Development Goals (MDGs) agenda as described by the Sustainable Development Goals (SDGs) and seeks to end all preventable deaths of women, children and adolescents and create an environment in which these groups not only survive, but thrive, and see their environments, health and wellbeing transformed [10].

In Zambia the major direct causes of maternal and neonatal mortality in Zambia arise from complications related to pregnancy and birth, such as hemorrhage, septicemia, obstructed labor, hypertensive conditions, as well as unsafe abortions. Indirect causes are multi-factorial and inadequate human resources and commodities and social-economic factors [11]. The majority of these maternal deaths could be prevented by ensuring access to good-quality maternal health services, such as antenatal and postnatal care, and skilled attendance during childbirth, including emergency obstetric and neonatal care addressing the socio-economic factors [11].

Zambia has been striving to reduce maternal mortality by ensuring universal access to maternal and child health care services. Various activities have been introduced in Zambia to improve maternal and neonatal health. Among the programmes include Safe Motherhood Action groups (SMAGS) and mobilizing access to maternal health services in Zambia (MAMaZ). However, indicators from the Demographic and Health Survey (DHS) indicate that there are still low maternal indicators [11], hence the aim of this study to explore women's expe- 
rience with socio-economic factors associated with perinatal morbidity and mortality affecting quality maternity care services in Mumbwa and Lusaka Districts of Zambia.

\section{Methodology}

\subsection{Study Area, Design and Population}

The study was carried out in Lusaka and Mumbwa districts of Zambia. The districts were conveniently selected considering their locations of being urban and rural. In addition, a first level hospital and a health centre were purposefully selected to make a total of four facilities as actual study sites. That is, Ngombe Health Centre and Kanyama First Level Hospital in Lusaka and Nangoma Mission Hospital and Mumbwa District Hospital in Mumbwa. All the health facilities provide comprehensive maternal and child health care services and were selected to reflect a representative cross section of women who use these facilities.

The study used Hermeneutic phenomenological design, a qualitative approach to answer the research question. There were four focus group discussions (FGDs), and each had a minimum of 11 women participants to a maximum of 12. We interviewed a total of 45 women across the study sites. To ensure homogeneity of the participants in each FGD, we requested a senior manager at each health facility to assist in purposefully identifying women who were at the facility seeking maternal health care services.

Women who were identified and selected were asked for their consent to participate in the FGD sessions at every health facility visited. To be guided during the course of the FGD sessions, the researchers used a discussion guide list to direct the flow and scope of the discussion during each session. The content of the FGD comprised socio-economic factors associated with perinatal morbidity and mortality in the following subtopics: 1) Women's feelings about the society, mothers and monetary roles in pregnancy and child rearing; 2) What women do to facilitate childbearing; 3) Whose role is it to prepare pregnant women for pregnancy and delivery?; 4) If the traditional preparation fails to work, what do you do?; 5) Do you think money contributes to successful labour and delivery?; 6) If you are to get all the money which you require, what would you do to make pregnancy, delivery and child-rearing enjoyable?; 7) If a child gets ill, who makes the decision to seek treatment at a Health Centre and 8) Is there anything else which contributes to illness or death of women and neonates in the period just before and after delivery of the child.

\subsection{Data Collection}

The focus group discussion guide (FGDG) was used to direct the flow of the discussion on women's experience with socio-economic factors associated with perinatal morbidity and mortality affecting quality maternity care services. It was developed, pilot tested through cognitive interviewing, and revised as needed (Rothgeb, 2003; Presser et al., 2004). The focus of the questions on the 
FGDG was on the socio-economic factors associated with perinatal morbidity and mortality at these facilities. A written informed consent was obtained from all the identified women who were willing to participate in the study before being included in the groups at each health facility that was visited. The eligibility criteria included being 18 years of age or older, having adequate knowledge or experiences related to childhood survival, and able to speak English, Ichibemba, Citonga or Chinyanja, and Silozi. The research assistants contacted the participants and gave the information sheet to inform the participants what the study was all about. The participants sat in a circular formation and consent form was signed indicating agreeing to participate. Two researchers conducted the focus group discussions (FGDs). During the FGDs, forward and backward translations were employed were there was need. A total of four FGDs were held with the women who were coming for postnatal care at the study sites. The FGDs were conducted between June and September 2017 in the local language spoken at each of the study sites. Each FGD was recorded with Olympus Digital Voice Recorder WS-852 (Olympus Corporation, Shinjuku, Tokyo, Japan).

\subsection{Data Analysis}

Manual transcription of the audio data was carried out for closer study of the transcripts. Each FGD was transcribed and read to acquire a sense and understanding of the whole text and to obtain ideas for further analysis. This involved vigorous and reflective study of each question. A process of open coding was applied, which revealed concepts in the responses that were then classified into categories. The connections between the categories became apparent in accordance with the coding. This led to the systematic development of the major themes to obtain ideas for further analysis. The additional themes were also identified upon review of the transcript. The text was coded and reviewed for pattern of consistency, variation, relationships between themes and exemplary cases or quotations [12] [13]. This involved rigorous and reflective study of the FGD, content analysis of audiotape recordings were transcribed into verbatim and identified the key words that were similar per study site. The field notes incorporated the transcripts. The FGD, audio recordings were transcribed by the research assistants, translated into English as needed, and field notes incorporated into the transcript. At least two translators were involved to confirm the authenticity of the transcripts. The transcripts and field notes were analyzed using the principle of content analysis (Polit and Hungler, 1999; Sarantakos, 1998). Transcripts were coded and analyzed using the ATLAS.ti 8.0 qualitative data software (ATLAS.ti Scientific Software Development GmbH, Berlin, and Germany). Deductive themes were determined a priori based on interview guides and key topics of interest based on literature review. Additional themes were also identified upon review of the transcripts. Text was coded and reviewed for patterns of consistency, variation, relationships between themes and exemplary cases or quotations [13]. 


\subsection{Ethical Approval}

This study was approved by the University of Zambia Biomedical Research Ethics Committee on reference number 003-06-16. Permission to conduct the study was sought from the Lusaka Provincial and District Health Offices and Central Province Medical Office, and Mumbwa District Medical Office. The Provincial and District Medical permission were obtained in order to gain access to health facilities that participated in the study. On accessing the facilities, permission was further obtained from the Nurse in-charge who also facilitated recruitment of eligible women. Written informed consent was obtained from all women included in the FGD before the commencement of each session and the Principal Investigator asked the women if they could be recorded during the sessions. The women were encouraged to ask questions, contribute and ask for clarity where need arose. The audio data collected was saved using authentication identifiers to ensure data confidentiality. The FGDs were conducted in preselected private spaces within the health facility.

\section{Results}

During the analysis the collected data was converted from audio data to text data that discussed the experiences of women with socio-economic factors associated with perinatal morbidity and mortality in Lusaka and Mumbwa Districts.

\subsection{What Are You Feelings about the Society, Mothers and Monetary Roles in Pregnancy and Child Rearing?}

\subsubsection{Monetary Roles in Pregnancy and Child Rearing}

Participant 1 Kanyama said that "money is important to an expectant mother to buy things for the baby and is also during delivery because you require money if you look at buying things for the baby you need money and others stay far from health centers and for them to move to and from the medical facilities they need money".

Participant 2 from Kanyama mentioned that "money is very good because when you deliver you can buy some food and eat. And sometimes a midwife may tell you that you are required to buy some things like blood". "Money is important but life is more important than money we use money to buy things to prepare for the unborn baby and also to help improve the health of an expectant mother because many women are dying and other women do not know their $H I V$ status while others refuse to be examined and others are scared of going to health centers for fear of being examined".

Participant 4 from Kanyama, said that "money does a lot of things and if you do not have money then you cannot survive. We use money when we are pregnant as there are some things we budget for the baby and during labor, and also for transport'. Participant 1, Ng'ombe. We also use money for scanning and at this clinic and we pay $K 70$ (\$7) each. At Ngombe, The $3^{\text {rd }}$ Participant said that the needs for the antenatal care have also increased and are different from the 
previous days, because when getting into labor you should wear a new dress and you need to have a maternity dress because if you go in a T shirt or a chitenge they will send you back, they will not send you back during labor but during antenatal because you need to prepare some dresses when you go for antenatal all the time. The midwives used to demand that after preparing for the bay they needed us to have a K500 to keep just for some emergencies. The third participant gave an example like when she went to deliver, she was referred to Levi Mwanawasa hospital because her baby was too big and for sure the money helped to hire a taxi. That money also helped for examinations that she had at the hospital because she delivered through a caesarian section and had to pay for transport again to go back home. She further said where sometimes they find that the ambulances are out to other clinics so that is there was no ambulance at the clinic and they always call for an ambulance from UTH why you need your own transport money to get to the other hospital where you have been referred to. Participant 4 said "it depends with some clinics".

On the clinic as for me I started at Chainama clinic before it was demolished and they just told us to prepare $K 250$ (\$25\%) for emergencies.

For us here at $\mathrm{Ng}$ ombe clinic they tell us to prepare $K 300$ (\$30) and kindly help us why these figures are different because these are local clinics.

Participant 6 said that she was not complaining about the money but she said that they are told to prepare at their clinics because that money is mine to use and not for the health worker. The K500 they told me to prepare was used by me and I appreciated how it worked.

The question you asked us on how money helps us? Money is very much needed when a woman is pregnant or even after birth. If a person is pregnant just as the other participant 1 explained it is true transport is needed because we stay very far. So transport money is required other than that you need to provide things for the baby. Another thing mentioned by the participant was that you need to eat a balanced diet so that you can have adequate and sufficient food for the mother and baby. Let me add something about what is required at the clinic, they ask for gloves, jik, and Razor blade Participant 4, in Mumbwa said another thing that we are required to carry from home is food in form of mealie meal, relish, and some drinks that an expectant mother can drink Participant 5.

In Nangoma participants 2 added that we use money mostly to feed families and just as we are with pregnancies, we need to have some money all the time so that in case of anything we can be able to book a taxi or sort out any problem that may arise.

\subsubsection{Society and Mothers Roles in Pregnancy and Child Rearing}

The participants 1 and 2 said that "the people with responsibility are our grandparents where as the third participant said a person who can take care of the pregnant woman or a mother with a newly born baby is a fellow woman such as a sister, an aunt, a mother or a grandmother as long as they are female. I cannot invite a man because after delivery I need to be birthed and helped to wash the 
wounds which a man cannot do".

Participant1 from Nangoma said that "my mother has a role to look after me during and after pregnancy, if my mother are not available to look after me my grandmother should look after me as I wait to deliver and if she is too old she can assign another younger person in the community to escort me because things are not easier since they will just leave me alone at the clinic". The second participant said "the way I see things myself is that the person who is responsible to look after me in pregnancy are your parents because the man is at work. Community members also help especially those from the extended family during child rearing by assisting in household chores and cooking for the mother after delivery".

Other women said the women in society and mothers simplify pregnancy, delivery and child rearing by getting traditional herbs to enable them to deliver quickly and they put in porridge or cold water. Others women facilitate pregnancy by giving you roots of a tree known as mizihimbilili, nakatenge and some beans or others will give you something to wrap around your waist to facilitate delivery.

\subsection{What Do You Do to Facilitate Child Bearing}

Participant 1 said that "they give us medicine like folic acid and ferrous sulphate which is yellow and red and this medicine helps us a lot so that when you deliver you can remain with some blood even after losing more blood. They also give us fansidar three times to prevent us from getting malaria. So if you mange to register and get the medicine you cannot be sick during pregnancy or after delivery. I also make sure that I am eating good food so that I do not cause problems to my body or the baby, but the mother from $N g$ ombe said that if a woman is pregnant they need to have a balanced diet and not to eat okra with soda because the baby cannot be health. You need to eat energy giving, body building and protective types of food so that you can have energy to deliver well. When I deliver I continue to monitor my diet so that I have sufficient nutrients and enough milk for the baby" Participant 1. Participant 2 further said "what we do as women, is that the moment the pregnancy turns three months old we should go to the health centre to register after being examined they will know the problem that you have and will monitor you till the day of delivery so that you do not face any problem together with the baby after delivery". Participant 3 mentioned that "what we do when we are pregnant we should go to the clinic so that we can be examined and given medicine for prevention as welp'. Participant 5 said that when we become pregnant we go for antenatal to register, when we register and they find us with any problem they will start giving us help, even when you deliver or you are breastfeeding or even when they find you that you are sick they continue to help until baby stops breastfeeding. For me to deliver well I do not do hard jobs and lifting heavy things.

At the clinic they tell us that "when it is time to go to for labor we need to 
have a bucket, plastic papers which is spread on the delivery bed, a clean chitenge material which is ironed and kept properly, a bottle of jik used to clean the place where you have delivered from, 6 pairs of gloves for returning mothers and 8 pairs of gloves for first pregnancies because they call for regular checkups then we are also to carry some pegs and if they tell me that I am carrying twins then I should carry 3 pegs (cord clamps) in case one of them does not work well, razor blade, cotton rolls, Candles, lambs in case of load shading", "Participant 1, 2, 3, \& 4."

The $5^{\text {th }}$ participant from Ng'ombe said that let me narrate what I saw at the 3 scanning centers where I had gone ... "laughs and explained I had gone for three scans because I really wanted a boy and went for the first scan which showed that I was carrying a girl but I did not believe, I went for the second scan which also showed a girl and then I went for the third to confirm ... everyone laughed ... so in Kaunda square they told me that I shall deliver on $15^{\text {th }}$ June, in Ng'ombe it was $16^{\text {th }}$ June and then at UTH it was $28^{\text {th }}$ June. So you can make an appointment with the Doctor on $28^{\text {th }}$ June and then you get lost because scans are done by human beings. You just estimate and not God, Fortunately I delivered on $16^{\text {th }}$ June".

The first participant in Mumbwa reviewed that "we were advised not to do some hard work and do some exercises such as playing football or jogging saying they can deliver fast" Participant 1 . The second participant said that "we need to do some exercise while you are pregnant like taking a walk to stretch your legs but there are also other exercises that you cannot do unless you are advised at the hospital". The participant further explained that "as for what happens when going home after your first child because I never knew that after delivery, a bleeding mother should not cook or put salt in relish. But hers is my question suppose you are just alone home? Other family members are not there?" Participant 2 asked a question, these issues being said here are they beliefs or facts according to medical findings?

The $3^{\text {rd }}$ participant said that "If you feel the pain prior to giving birth you need to walk around and not just sit because you can delay to deliver, you can even do some work and not hard work, you can also go and bath".

Participant 4 and participant 1 in Nangoma "laughs ... at home I will be doing all the works such as washing, cooking and everything. When you are expecting there will be a relative that will come to help you with some work until you deliver. So you can invite a family member to come and be with you". The $5^{\text {th }}$ Participant said "we are supposed to do some exercises such as walking and jogging and we are told to walk so that the baby can come out fast. After delivering you continue walking so that you can be strong". Participant 6 said that, "for me since I have just delivered when I go home, I will not be doing anything, and I will just be bathing, eating or sleeping. I cannot even cook anything because I am not supposed to put salt in the relish. I can wash plates and dishes I can also fetch some water but I cannot cook and put salt in relish or any type of food". 
The $7^{\text {th }}$ participant reported that "when women are discharged from the clinic after delivery they should just go home straight and enter the house and stay there for a period of one month. I cannot even go fetch water because they say that I can get sick and that I will have backache because bucket containers are heavy. Salt is said to be the cause for a disease known as the disease 'Kabe' (Mumbwa language) Kabe (sickness) causes sores on the throat, face or nose that never heals, a woman should not add salt in the first four weeks after delivery".

\subsection{Whose Role Is It to Prepare Pregnant Women for Pregnancy and Delivery?}

Participant 1, Kanyama said that "health personnel are responsible. Where we have come from it is me and my husband who are responsible. How my husband responded to my pregnancy was that he used to escort me to the antenatal clinic all the time. Issues of food he used to research to know the right food that I needed and he would also provide me. He also bought for me maternity dresses each time he found a good one. He also bought clothes for the baby and constantly monitored me in terms of the domestic all duties till I delivered because I had complications with my pregnancy. Sometimes my legs were swelling but he would help massage me" (Participant $1 \& 2$ ).

The $3^{\text {rd }}$ participant said that "when you are preparing for the baby, the one who is responsible is the father because he is the one who provides money so that you can buy things for the baby before the labor starts".

Participant 4 said that "My husband and I are responsible and followed by the workers at the clinic". Participant 5 thought that "it was the father and the nurse" while participant 6 said "it was the father and the mother", while participants $8 \& 9$ said "it is the father just like my husband worked to prepare for the baby". The $10^{\text {th }}$ participants said that "it was the grandmothers, and Church leaders only teach us on how to take care of ourselves when we are pregnant and how to look after the baby when it s born". Parents also teach about what we are supposed to eat and types of work we are supposed to do. But for me they were far but sometimes they would call to ask if the legs were getting swollen and so they could and tell me to lift my legs and eat what I want rather than starving.

The first participant from Ng'ombe said "it was her sister who helped her and the $2^{\text {nd }}$ participant it was her mother in law who waited for her and when delivered baby would cry the mother in law would tell her to breastfeed the baby and she said that she felt very secure that it was the mother in-law who was told those things to tell her". The $3^{\text {rd }}$ participant said "it was her parents and her husband who took her to the hospital and she was advised not to shout and struggle as she would make the baby tired and make the baby die or they would refer me to University Teaching Hospital. The one who helped me was my mother as she is the one close to me because my mother in law passed away". The fifth participant said that "it was the mother and husband who took her there but she was not prepared for the current pregnancy and made consultations about how un- 
happy she was with the pregnancy as they had agreed to only have a child after 10 years but got pregnant on her $8^{\text {th }}$ year and being on family planning injection and she said she had been feeling pain in the stomach and she was told that she was fine it might be worms until she went to Chainama clinic for a scan and was found to be pregnant. The one who helped me is my sister, my mother was in Mansa where she had gone to stay".

The participants 1 and 2 said that "the people with responsibility are our grandparents where as the third participant said a person who can take care of the pregnant woman or a mother with a newly born baby is a fellow woman such as a sister, an aunt, a mother or a grandmother as long as they are female. I cannot invite a man because after delivery I need to be birthed and helped to wash the wounds which a man cannot do".

Participant 1from Nangoma said that "if my parents are not available to look after me my grandmother should look after me as I wait to deliver an if she is too old she can assign another younger person to escort me because things are not easier since they will just leave me at the clinic". The second participant said "the way I see things myself is that the person who is responsible to look after you are your parents because the man is at work".

Participant 5 said that "traditional birth attendants can deliver but these days we are discouraged from going to traditional birth attendants to reduce on maternal mortality because the baby can come in a different way that may only need health experts and when you are in a health institute they can save your life and that of the baby".

Other women get traditional herbs to enable them to deliver quickly and they put in porridge or cold water. Others will give you roots of a tree known as mizihimbilili, nakatenge and some beans or others will give you something to wrap around your waist.

\subsection{If the Traditional Preparation Fails to Work What Do You Do?}

The women gave the following responses such as: we want to go and ask at the clinic but we are scared that we may not be welcomed well and sometimes there may be no time to be counseled well because there are long ques here. Participant 2 said that this issue of getting traditional medicine as God is the only one who knows the day of conceiving and the day of delivery.

Participant 1. "At Ng'ombe said that she had heard that there are some herbs to take that broaden the birth canal and protect you in case there are people who bewitched you or may be your husband has gone out with another woman while you are pregnancy". Participant 2 said "that an old woman called me and asked me why I had delayed to deliver? The old woman advised that once labor starts I should buy a lot of tea bags of any type and put in a cup then put a little sugar and take it at the moment when you get to the clinic and you will deliver quickly, but I never followed that. Participant 3: was also advised to look for a tree by the name of Chishopolela and that I should dig the roots and put them in a cup with 
water and take as I shall not delay to deliver". The $4^{\text {th }}$ participant believed in an advice which states that "my husband should not put on a waist belt as it is believed that a belt can tie the baby in the wound. However the participant reported that she was in labor for 5 days while her husband was wearing trousers without belts and never delivered". Participant 4 said that "her mother's friend was told that she should get dirty socks from the husband when labor and that he should put them in water and that she should drink using leaves and that the water should drop down for me to deliver fast". The participant 6 said that " $I$ was told to get soil from the road and add water to drink but I did not do that because I never believed in all these theories". Participant 8 reported that "after delivery some people say there are some charms that a mother should administer to protect the baby from sickness that come when the father goes out with another woman when the baby is very small". Participant 10 Said that "some babies are born with green things on the belly that are known as longolongo for these to disappear they use herbal medicine such as Kalembula and pumpkin leaves".

The participant 7 from mumbwa said that "when the traditional way fails we come to the clinic because here we find help". And in Nangoma participant 5 said that "mothers in the village if there are complication the people who administered those herbs have to quickly look for transport to rush their patient to the hospital because the herbs can even cause problems in the stomach".

What Is Done by Those with Much Money Which Is Not Done by People with Less Money? (If You Are to Get All the Money Which You Require, What Would You Do to Make Pregnancy, Delivery and Child-Rearing Enjoyable?)

Participant 1 at Kanyama said that "people who have money have easy access to the services because they have money such that if they come to this clinic and find long ques they will decide to go to a private hospita?'. At the private hospital the woman will receive the help they need quickly and even go back home earlier. If you go to public hospitals you will find harsh nurses who will just be shouting at you even when you are in great pain, you will be scared to say it because you are scared of being shouted at. Yes there is a lot of segregation and shouting at the hospital, nurses here can shout very much and we are evens cared to ask where the toilet is.

Participant 2 said that "when you have money it contributes to help a pregnant woman to take care of the pregnancy and the woman wants a lot of food and even when labor pain starts you will be required to go to the hospital and if you have money you can hire a taxi because you cannot use a bus when you are in labor". Participant 3 said that "there was a big difference between people with money and those without because if you do not have money it is difficult as the taxi will not agree to take you to the clinic".

Participant 1 said that "I think money does not help in any way it is just God who helps and not money but there are babies who get sick and die even when 
they have money so it is just God who helps".

Participant 2 in Mumbwa said that "money works to every human being whether they are pregnant or not, money is good". Participant 4 said that "I think money helps to buy the requirements".

Participant 2 at Nangoma said that "Yes money helps a lot sometimes when you are delivering you can have a normal delivery but other times you may have complications that may require some money and when you do not have money then you can have a problem. Lack of money is what makes some mothers camp at the mothers' awaiting their delivery".

Participant 4 said that "money helps in many ways sometimes you can be referred to UTH and that money can help you because they will take you by ambulance but you should find your way back".

Participant 1 in Kanyama said that "what I can do if I had enough money is first come to Kanyama hospital and go to better clinic like Mums care clinic because I have money to go where I know that they will attend to me well. I can also buy anything during my pregnancy". The fourth participant reported that "the children are dying because of not having drugs, if they prescribe medicine for you at the time when you do not have money the baby will die".

\subsection{How Do You Look after Newly Born Babies?}

Participant 1 in Kanyama said that "when the baby is born you must feed for 6 months without giving them water until they reach 6 months. If the mother is $H I V$ positive never attempt to give the baby any food".

Participant 4 said "that there is a type of sickness like fever but I do not believe that there is someone who can bewitch my baby as if they are the ones who gave me the baby. For me I take the child to the clinic and do not give them anything. I believe that what cause the sickness are dirty food and the weather". Participant 4 said that "her baby was just crying because of stomach problems but they have restricted us not to give any baby who is below the age of six months anything to take, but for me we bought some medicine known as Bonnisan that we started administering because of the stomach pain".

At Ng'ombe Participant 1 said that "the baby is supposed to be clean so we wash their clothes and nappies as a mother no one is supposed to tell me that the child is sick because even the way they suck the milk I can tell that something is wrong with the baby". Participant 9 from Ng'ombe said that "she was told that there are some charms that are put in the bathing water for the baby so that it can grow health with power and a big body". Participant 10 said that "the herb is made from vibuyu tree and that because the tree is big even the baby can be big. The parts of the tree are put in a container and that is where you get some water to mix with the bathing water for the baby but I do not know how long the process takes". Participant 5 said that "if the baby is sick and the hospital fails to help I go to the church and when they conduct prayers for the baby it will recover because the baby is innocent and righteous". Participant 7 said that "the 
way this baby is now I am not supposed to leave him home and I go for a long time he will be sick".

\subsection{If the Child Gets Ill Who Makes the Decision to Seek Treatment at a Health Centre?}

Participant 1 said that if "it is the parents that decide together to take the baby to the clinic so that the baby can be examined by medical doctors. She further said that the baby should not be taken to any other place other than the clinic". The $2^{\text {nd }}$ participant said "the person who decides it is me the mother and no one else".

Participant one from Ng'ombe said that "it is me the mother because sometimes the father is at work and cannot decide about the welfare of the baby".

\subsection{Is There Anything Else Which Contribute to Illness or Death of Women and Neonates in the Period Just before and after Delivery of a Child?}

Participant 2 said that "for me what I can contribute is that the biggest causes of death are the nurses. Like what happened during my delivery I went to tell them when I was about to deliver that they check on me because I felt that the baby was now coming but instead they shouted at me and dropped me out of the delivery bed and said that the birth canal had not yet opened. I obeyed and went to wait at the reception. Later I went outside where my mother was and the moment I got to where my mother was, the baby came out and was born from outside. So the causers were the nurses because I had told them how I was feeling and If I had died or the baby they would have been the causes of the mortality". Participant 3 "in my thinking as a woman let me go back a little bit some of us do not think well. In the scene that we run away when they want to test us at the clinic, even after delivery we always want to argue when we are given some advice or even when we are told we are positive we will continue doing things our own way till the child gets the virus". Participant 4 said that "the nurses, who work here especially those who work in labor ward, please go and tell those in authority that we are not being cared for well as women. Some of us who have given birth before are always slapped that we are not supposed to shout even when we are in pain. But is it an offense to shout when you are in pain"? Participant 5: The new beds that they have brought in labor ward are too high if you tell them that the baby is about to come they do not come immediately to see if what you are saying is true and they have to put rails on the bed, which if a baby falls on them can cause death. When you get on the bed, on the side there is something like a rail, so just there when the baby comes out, he drops on the metal.

Participant one at Ng'ombe said that sometimes its late referrals to a bigger health center and also some women are reluctant to take folic acid and the drug for blood and when you deliver and they find that you have no blood then you can die. Participant 3 said that "sometimes babies can die if you delay to deliver because they become tired". Participant 4 said that "some other women who use 
traditional charms or herbs find problem because the herbs can cause the womb to burst from inside". She further said for babies we just hear that it has died because of being exposed in the cold, and participant 6 said other women develop high Blood Pressure and they die and some babies get chocked when being born and they can die.

In Mumbwa participant 5 said other women die of HIV, severe headache because we recently heard that one woman died of headache and another one died of chest pains. Participant 6 said that if a woman bleeds a lot when delivering she can die. She further reported that babies die because they are squeezed during labor by their mothers. Participant 7 said that "I thinks women die of the common diseases such as malaria, excessive bleeding after delivery, HIV and some other diseases that we may not know very well'. She further said for babies we only hear that it has died after one week but we do not know what causes the death.

Participant 4 from Nangoma said that she heard that when you sleep with another man while you are pregnant you can die when delivering or if your husband also goes to sleep with another woman while you are pregnant then you can die while delivering. Participant 5 said that sometimes there are people who are jealousy in the compound that causes complication during the delivery that is why we see some women being operated on when delivering, jealousy in the compound that causes some people to die.

\section{Discussion}

\subsection{What Are Your Feelings about the Society, Mothers, and Monetary Roles in Pregnancy and Child Rearing?}

\subsubsection{Monetary Requirements}

In Zambia, government hospitals do not charge for the deliveries but ask women to contribute in material forms such as jik, bucket, and plastic paper to cover the bed and baby layette. Women outlined many issues related to the childbearing women that included money to save (which is different across institutions) and the woman said that the Money is important to an expectant mother in order to buy things for the baby and is also useful during delivery because you require money to buy. In this study, women demonstrated that having money during pregnancy simplifies the burden of pregnancy, delivery and child rearing for the health care providers, mothers and the society. Some studies have also revealed that despite the desire for women to want a family, some level of financial security was necessary prior to childbearing [14]. Economic stability has been identified as important in influencing maternal health care service utilization behavior of women, a study in more than 50 countries showed that on average more than $80 \%$ of births were attended for the richest women compared with only $34 \%$ of the poorest women [15] [16]. Studies revealed that most pregnant women would prefer home delivery in order to get care and comfort from their families as well as to take advantage of low cost of care received from the TBAs [17]. This find- 
ing demonstrates that lack of money during pregnancy and child birth could impact morbidity and mortality in perinatal period.

\subsubsection{What Are Your Feelings about the Society and Mothers in Pregnancy and Child Rearing?}

Women felt society and mothers simplify pregnancy, delivery and child rearing by getting traditional herbs to enable them to deliver quickly and they put in porridge or cold water. Others women facilitate pregnancy by giving you roots of a tree known as mizihimbilili, nakatenge and some beans or others will give you something to wrap around your waist to facilitate delivery. Grandparents and fellow women in the society had a role to bath both the child and mother's body and wounds which a man cannot do. Community members also help especially those from the extended family during child rearing by assisting in household chores and cooking for the mother after delivery. Other studies have also found similar result like this study, women felt that mothers in law, mother to the woman and other females in the community had a role to assist a woman during pregnancy and after delivery [18] [19] [20] [21].

\subsection{What Do You Do to Facilitate Child Bearing}

\subsubsection{Traditional Beliefs}

The study found that post natal mothers should not cook or put salt in relish as it causes diseases like "Kabe" (presents as sore on the throat, face or nose that does not heal). Household activities should start after a period of one month, all a woman does is to breast feed baby, eat and sleep. This is good as it facilitates rest for the woman. These finding are similar to some studies that found that women from certain ethnic groups are forbidden to eat certain foods during pregnancy, thus impacting on their nutritional status, household confinement is custom, which usually lasts for a month, although in the cases of the Hui it can last as long as 40 days [22] [23]. In other studies, postpartum women are viewed as being "unclean" and therefore a threat to other members of the community, which makes some women from these minorities reluctant to have hospital deliveries or to leave the home for postpartum checkups [18] [23].

\subsubsection{Facilitating Childbirth}

The women reported that during pregnancy they are given medicines by health care workers to protect them from malaria and loss of blood. They were advised to eat balanced diet to avoid problems for mother and baby. They reported that information on importance for attending antenatal and doing the requested investigations. They were also told the importance of rest and avoid hard jobs during pregnancy. Having the required resources prescribed by the health practitioners, for instance, jik, plastic paper, bucket and gloves. Mild exercises like washing, and working around as well as getting a relative to stay with during pregnancy facilitates child birth [24]. Women in this study viewed care providers not only as sources of information, but also as sources of experienced knowledge in facilitating child birth. Apart from health care advice, women mentioned tra- 
ditional preparations that facilitate child birth. These findings are similar to those found by [18] where some pregnant women mentioned the use of cyclamen (a plant which grows in Mecca, Saudi Arabia) for an easy natural birth.

\subsection{Whose Role Is It to Prepare Pregnant Women for Pregnancy and Delivery?}

Health care workers (nurses) are responsible for safe delivery. Others mentioned mothers, sisters, sister's in-law and mother's in-law as individuals responsible since husbands have to go for work. Sisters and mothers in-law and grandparents also teach mothers how to behave in during labor (no shouting during labor as baby can be tired). Husbands were mostly responsible for buying food for mother and baby, baby clothes, they could not be with women after delivery as they went for work most of the times and they cannot bath baby or woman after delivery. These finding are in line to those of [18] that found that mothers and grandparent were responsible for taking care of labor and the new born. This study also revealed that church leaders are responsible as they teach on care during and after delivery, these results were also confirmed by [19]. Traditional birth-attendants are also mentioned as source of social support though now women are being discouraged to reduce death. These study findings are similar to result of [18] [20] [22] that showed that many of the research participants saw women's preparation for childbirth as a positive activity fully supported by spouse, family and community members. Mothers and grandmothers were primary sources for information about birth preparation.

\subsection{If the Traditional Preparation Fails to Work What Do You Do?}

Women mentioned that they only come to the hospital when traditional ways fail. They are scared to mention the use of herbs at the clinic as they fear to be sent away and poor welcome. Some do not mention because of and others wait for God's intervention as he is the only one who knows the day of conceiving and the day of delivery, they avoid the health care facilities due to long queues and nurses have no time to counsel patients. This finding is similar to that of [18] [19], women looked up to God for intervention when traditional preparation failed to work.

\subsection{Herbal Medicine Used}

Traditional medicines were taken to broaden the birth canal and protect the mother in case there are people that may bewitch the woman or her husband has gone out with another woman. Adding a lot of teabags in a cup with water and drink when in labor enhances labor time. Husbands must not wear a waist belt when wife is in labor. Drinking socked dirt husband socks was believe to facilitate labor and delivery, drinking roots of Chishopolela tree when labor starts was also mentioned to precipitate labor. The dirt socks could lead to diarrheal diseases and the roots could interfere with hospital medication. Food restrictions 
may lead to anemia that may lead perinatal morbidity and mortality. Denial or avoidance of such foods can adversely affect the health of pregnant women by increasing their chances of suffering from Anemia. Food restrictions and taboos constitute a major area of cultural impact that creates problems for pregnant women. It was found that women use herbs as the first choice of treatment during labor, this may cause delay in seeking health care and therefore can result in perinatal morbidity and mortality. These findings are consistent with other studies that revealed that sociocultural practices have been identified as playing a significant role on the use of health care by pregnant women [24] [25]. Social beliefs and practices however run through both rural and urban areas of the districts. Some studies, however, report that cultural practices had no negative effect on pregnancy. Deliveries conducted by untrained TBAs are associated with frequent maternal mortalities due to sepsis from frequent vaginal examination with bare hands and post-partum hemorrhage resulting from inability to recognize danger signs [24].

\subsection{What Would You Do to Make Pregnancy, Delivery and Child Bearing Enjoyable?}

Women would prefer to deliver from a private hospital as they thought the care would be excellent. They can use the money to buy whatever they require during pregnancy and also buy medicine for the baby if prescribed to avoid losing baby when hospitals have run out of drugs. These findings are similar to those found by [26] in Ethiopia, it was found that a statistically significant association between household wealth and assistance during delivery with women in the rich and richest wealth groups more likely to have professional assistance during birth. In India, among women of medium and high standard of living, the odds of delivery in an institution were 1.4 times and 2.3 times respectively than those of women with a low standard of living [27].

\subsection{How Do You Look after Newly Born Babies?}

Women reported that you feed baby milk for 6 months without giving water or any food. If the mother is HIV positive never attempt to give bay any food. Child should be taken to the clinic when ill and only give prescribed medication. The other woman said she bought Bonnisan and gave the baby who she suspected had stomach pain. Bathing the baby and observing the way baby sucks is important in the care of the baby. Others added charms in bathing water (from Vibuyu tree so that baby is as big as the tree) so that baby grows health with power and big body. Some took baby to church if hospital fails to offer the necessary help so that prayers are conducted for baby to recover. These findings are similar to those of [18] [19] that found that some women followed health care professional advice while other used traditional preparations to take care of the new born.

\subsection{Who Makes the Decision to Seek Treatment When Child Is Sick}

Some women said mother, mother-in-law or grandparents decide together to 
take baby to the clinic so that the baby can be examined by medical doctors. The other woman said the mother is the one who decides and no one else. Another woman said the mother decides because sometimes the father is at work and cannot decide about the welfare of the baby. These findings are similar to those found by UNFPA that emphasized the role of mothers-in-law to be very important regarding decision making on maternal health issues, and care of infants and children. Men play a lead role in managing family income, though the extent of this varies between the different communities. In traditional Miao society, the mother-in-law decides whether or not, and where, to visit doctors [23].

\subsection{Anything Else Which Contribute to Illness or Death of Women and Neonates in the Period Just before and after Delivery}

Nurses were mentioned to be the biggest cause of death. Women who avoid investigations, for example HIV Test and poor nursing care also contributes to mortalities. The high beds in labor ward with metal sides can contribute to death especially if the nurse comes late and baby falls off the baby. Reluctance to take drugs for blood, and prolonged delivery if child is tired, use of herbs can cause wound to burst, exposure to the cold, pre-eclampsia and baby chocking when being born causes mortality. Diseases like HIV, malaria, severe headache, bleeding a lot during delivery and squeezing baby by mothers during labor were mentioned as cause of mortality. Others mentioned that cause of death for babies was not known, while some other reasons given included having sex with another man while pregnant, your husband sleeps with another woman or jealous people in the compound can cause complications like being operated on during delivery. This finding are in line with those of [20] that stated that Providers need to consider the ways in which their attitudes and behaviors send unwelcoming messages to African American women seeking prenatal care or childbirth classes. Negative and patronizing attitudes on the part of service providers were described as barriers to utilizing $\mathrm{MCH}$ services by many respondents [23] [28] [29].

\section{Limitations of the Study}

The interviews were conducted at the health facilities were the women received maternity care services, there is a possibility that this might have influenced their responses. Considering the fact that the researchers were from the highest learning institution (University of Zambia) of the land, some women might have been intimated and discussed in the manner that pleased the researchers. Since some researchers were men, there is a possibility that some women could not open up during the discussion.

\section{Conclusion}

Women demonstrated that having money during pregnancy simplifies the burden of pregnancy, delivery and child rearing for the health care providers, 
mothers and society. Women are still ignorant and believe in myths and need information on the dangers of depending on herbs and God but also seek help from qualified medical personnel when labor starts. Women should also avoid using herbs in the care of the newborn. The attitude of the nurses contributes to women fearing to open up and mention herbs or any medication they took to precipitate labor before seeking help from health practitioners. Nurses' attitude also needs to change to ensure women prefer health care institutions for delivery. Nurses were mentioned as the cause of morbidity and mortality among women and newborn. Despite the attitude of health care providers, women still rely on the expertise of trusted care providers, such as midwives and obstetricians, in order to facilitate the delivery of a healthy baby.

\section{Recommendation}

There's a need for training of Nurses and other health care workers on self-awareness of attitudes. Women should be empowered with resources that facilitate labor and delivery. Midwives and health care providers should take responsibility for evaluating and correcting the beliefs and traditional practices of the community. Training should be planned for raising awareness in order to support beneficial practices and prevent harmful ones.

\section{Acknowledgements}

We would like to acknowledge the financial support provided by the Norwegian Agency for Development (NORAD) through the Norwegian Programme for Capacity Development in Higher Education and Research for Development (NORHED) QZA-0848 QZA-MW-13/00032 Grant. The author's further wish to acknowledge the following for supporting the project: The Provincial and District Health Directors in-charge of the sites used for data collection, the health facility staff, the women and research assistants who participated in this study.

\section{Author's Contribution}

All the authors read and approved the paper.

\section{Conflicts of Interest}

The authors declare no conflicts of interest regarding the publication of this paper.

\section{References}

[1] Alkema, L., Chou, D., Hogan, D., Zhang, S., Moller, A.B., Gemmill, A., et al. (2016) Global, Regional, and National Levels and Trends in Maternal Mortality between 1990 and 2015, with Scenario-Based Projections to 2030: A Systematic Analysis by the UN Maternal Mortality Estimation Inter-Agency Group. The Lancet, 387, 462-474. https://doi.org/10.1016/S0140-6736(15)00838-7

[2] WHO (2015) Trends in Maternal Mortality: 1990 to 2015: Estimates by WHO, UNICEF, UNFPA, World Bank, and the United Nations Population Division. 
WHO, Geneva.

[3] Conde-Agudelo, A., Belizan, J.M. and Lammers, C. (2004) Maternal-Perinatal Morbidity and Mortality Associated with Adolescent Pregnancy in Latin America: Cross-Sectional Study. American Journal of Obstetrics and Gynecology, 192, 342-349. https://doi.org/10.1016/j.ajog.2004.10.593

[4] Patton, G.C., Coffey, C., Sawyer, S.M., Viner, R.M., Haller, D.M., Bose, K., Vos, T., Ferguson, J. and Mathers, C.D. (2009) Global Patterns of Mortality in Young People: A Systematic Analysis of Population Health Data. The Lancet, 374, 881-892. https://doi.org/10.1016/S0140-6736(09)60741-8

[5] Gina, N. (2009) Women's Experience of Prenatal Care: An Integrative Review. Journal of Midwifery \& Women's Health, 54, 226-237.

https://doi.org/10.1016/j.jmwh.2009.02.003

[6] Say, L., Chou, D., Gemmill, A., Tunçalp, Ö., Moller, A.B., Daniels, J.D., et al. (2014) Global Causes of Maternal Death: A WHO Systematic Analysis. Lancet Global Health, 2, e323-e333. https://doi.org/10.1016/S2214-109X(14)70227-X

[7] Blencowe, H., Cousens, S., Jassir, F.B., Say, L., Chou, D., Mathers, C., et al. (2016) National, Regional, and Worldwide Estimates of Stillbirth Rates in 2015, with Trends from 2000: A Systematic Analysis. The Lancet Global Health, 4, e98-e108. https://doi.org/10.1016/S2214-109X(15)00275-2

[8] WHO (2018) Maternal Mortality; Fact Sheets. WHO, Geneva.

[9] UNICEF (2015) Levels and Trends in Child Mortality. Report 2015. The Inter-Agency Group for Child Mortality Estimation (UN IGME) UNICEF, WHO, the World Bank, United Nations Population Division, New York.

[10] United Nations (2015) Global Strategy for Women's, Children's and Adolescents' Health, 2016-2030. UN, New York.

[11] Central Statistical Office (CSO) [Zambia], Ministry of Health (MOH) [Zambia], and ICF International (2014) Zambia Demographic and Health Survey 2013-14. Central Statistical Office, Ministry of Health, and ICF International, Rockville.

[12] Stanley, P., Mick, C.P., Judith, L.T., Elizabeth, M., Jean, M., Jennifer, R.M. and Eleanor, S. (2004) Methods for Testing and Evaluating Survey Questions. Public Opinion Quarterly, 68, 109-130. https://doi.org/10.1093/poq/nfh008

[13] Jennifer, R.M. (2003) Questionnaire Development, Evaluation, and Testing Methods (QDET) Conference; Good Discussions, Debates, and Dining in Charleston. Bulletin of Sociological Methodology, 77, 35-61. https://doi.org/10.1177/075910630307700105

[14] Montgomery, K.S., Green, T., Maher, B., Tipton, K., O’Bannon, C., Murphy, T., McCurry, T., Shaffer, L., Best, S. and Hatmaker-Flanigan, E. (2010) Women's Desire for Pregnancy. The Journal of Perinatal Education, 19, 53-61. https://doi.org/10.1624/105812410X514404

[15] Kalule-Sabiti, I., Amoateng, A. and Ngake, M. (2014) The Effect of Socio-Demographic Factors on the Utilization of Maternal Health Care Services in Uganda. African Population Studies, 28, 515. https://doi.org/10.11564/28-1-504

[16] Gill, K., Pande, R. and Malhotra, A. (2007) Women Deliver for Development. The Lancet, 370, 1347-1357. https://doi.org/10.1016/S0140-6736(07)61577-3

[17] Choudhury, N., Moran, A.C., Alam, M.A., Ahsan, K.Z., Rashid, S.F. and Streatfield, P.K. (2012) Beliefs and Practices during Pregnancy and Childbirth in Urban Slums of Dhaka, Bangladesh. BMC Public Health, 12, 791.

https://doi.org/10.1186/1471-2458-12-791 
[18] Murat Öztürk, D., Uluşen, M., Yılmaz, G. and Aydı, H. (2019) Evaluation of Knowledge and Attitudes Related to Traditional Practices Regarding the Care of Pregnant, Postpartum Women and the Newborn. Mersin Üniversitesi Tip Fakültesi Lokman Hekim Tip Tarihi ve Folklorik Tip Dergisi, 9, 55-65. https://doi.org/10.31020/mutftd.449980

[19] Roudsari, L., Zakerihamidi, R.M. and Khoei, E. (2015) Socio-Cultural Beliefs, Values and Traditions Regarding Women's Preferred Mode of Birth in the North of Iran. International Journal of Community Based Nursing and Midwifery, 3, 165-176.

[20] Abbyad, C. and Robertson, T.R. (2011) African American Women's Preparation for Childbirth from the Perspective of African American Health-Care Providers. The Journal of Perinatal Education, 20, 45-53. https://doi.org/10.1891/1058-1243.20.1.45

[21] Mlotshwa, L., Manderson, L. and Merten, S. (2017) Personal Support and Expressions of Care for Pregnant Women in Soweto, South Africa. Global Health Action, 10, Article ID: 1363454. https://doi.org/10.1080/16549716.2017.1363454

[22] Gedamu, H., Tsegaw, A. and Debebe, E. (2018) The Prevalence of Traditional Malpractice during Pregnancy, Child Birth, and Postnatal Period among Women of Childbearing Age in Meshenti Town, 2016. International Journal of Reproductive Medicine, 2018, Article ID: 5945060. https://doi.org/10.1155/2018/5945060

[23] UNFPA (2011) Study on Traditional Beliefs and Practices Regarding Maternal and Child Health in Yunnan, Guizhou, Qinghai and Tibet.

[24] Otoo, P., Habib, H. and Ankomah, A. (2015) Food Prohibitions and Other Traditional Practices in Pregnancy: A Qualitative Study in Western Region of Ghana. Advances in Reproductive Sciences, 3, 41-49. https://doi.org/10.4236/arsci.2015.33005

[25] Omane-Adjakum (2010) Medicines Usage in Pregnancy. Kwame Nkrumah University of Science and Technology, Kumasi.

[26] Dagne, E. (2010) Role of Socio-Demographic Factors on the Utilization of Maternal Health Care Services in Ethiopia. Department of Public Health, Umea University, Umeå.

[27] Ram, F. and Singh, A. (2006) Is Antenatal Care Effective in Improving Maternal Health in Rural Uttar Pradesh? Evidence from a District Level Household Survey. Journal of Biosocial Science, 38, 433-448.

[28] Sofolahan, Y.A. and Airhihenbuwa, C.O. (2012) Childbearing Decision Making: A Qualitative Study of Women Living with HIV/AIDS in Southwest Nigeria. AIDS Research and Treatment, 2012, Article ID: 478065. https://doi.org/10.1155/2012/478065

[29] Jansen, I. (2006) Decision Making in Childbirth: The Influence of Traditional Structures in a Ghanaian Village. International Nursing Review, 53, 41-46. https://doi.org/10.1111/j.1466-7657.2006.00448.x 